\title{
Further Observation with Thalidomide in Lepra Reactions
}

\author{
J. SHESKIN, M.D.*
}

Thalidomide was recently reported to exert a rapidly beneficial effect in the lepra reactions of lepromatous leprosy patients $\left.\left({ }^{1}\right){ }^{2}\right)$. This paper reports further experience with this drug over a I o-month period in thirteen patients who suffered from such reactions.

\section{CLINICAL MATERIAL AND METHODS}

Twelve of the patients had lepromatous leprosy; one patient had been diagnosed as borderline type. Ten were males and three were females, aged 23 to 54 years. Thalidomide was not given to female patients in whom there was thought to be a possibility of pregnancy occurring.

Most of the patients had been treated for lepra reactions, previous to November I 964, with courses of intramuscular stibophen, i 5 to $20 \mathrm{ml}$, given over a period of five days. If this failed to control the reaction steroids were given, the usual drug being prednisone 20 to $30 \mathrm{mg}$. per day, often with the addition of intramuscular A.C.T.H. 20 to 60 units per week. In some cases doses of this order had to be maintained for months or even years; attempts to reduce the maintenance dose resulted in recurrences of lepra reaction. Such patients thus developed many of the undesirable effects associated with long-term steroid therapy, and in addition still suffered from reaction from time to time. The frequency of reactions among the I 3 patients as a group prior to November I 964 was between once per week and once in two months.

Owing to the limited number of patients surveyed only a simple comparison has been attempted between the response to thalidomide during a lepra reaction with that of a placebo tablet of similar appearance and taste. The tablets were either given alone or together with existing steroid and/or dapsone (diamin-diphenyl-sulphone) therapy. The total number of reactions studied during this period was 22. In three patients only one reaction occurred, whilst 19 reactions occurred in the other ten patients. An account of the treatment of one patient who suffered four reactions since November I964 illustrates the method employed in trying to assess the efficacy of thalidomide.

In November I 964 a 46 -year-old man suffered from a reaction in spite of a maintenance dose of dapsone, I oo mg. per day, prednisone $20 \mathrm{mg}$. per day and A.C.T.H. 20 units three times a week. When thalidomide (I oo $\mathrm{mg}$. every 8 hours) was added to the existing regimen, clinical improvement was noted within 24 hours. After three days both thalidomide and dapsone were stopped, and the steroids gradually withdrawn. In December i 964 a severe reaction followed. There was no spontaneous remission after 48 hours, and treatment with thalidomide ( I oo mg. 8-hourly) alone was started. The patient responded rapidly, as he had done a month previously. Ten days later when thalidomide was stopped no immediate reaction followed. This patient in the past had always suffered reactions when receiving dapsone without steroids. A week later, therefore, dapsone was reintroduced (I oo $\mathrm{mg}$. per day) and ten days later a reaction occurred. The dapsone was continued with the addition of placebo tablets for two days, but without clinical change. Without reducing the dose of dapsone, ioo $\mathrm{mg}$. thalidomide were given three times daily, instead of the placebo. Dramatic improvement was seen within 12 hours. After one month both dapsone and thalidomide therapy were discontinued, and the patient remained without treatment until a further reaction occurred after four weeks. Thalidomide was then given alone. The result was as on the three previous occasions. Since then the patient has continued free from reaction on $400 \mathrm{mg}$. thalidomide per day

* Department of Dermatology, 'Hadassah' University Hospital, and the attached 'Hansen' Government Hospital, Jerusalem, Israel. Head of Department, Prof essor F. Sagher. 
for three months, and subsequently on $200 \mathrm{mg}$. per day for three months.

In similar fashion, 22 reactions were treated with 34 assorted therapeutic trials. There were five drug combinations: dapsone plus placebo, placebo alone, dapsone plus prednisone plus thalidomide, dapsone plus thalidomide, and thalidomide alone.

Urinalysis was performed before starting thalidomide treatment, and fortnightly thereafter; as were the following blood examinations: haemoglobin, white blood count, differential count, urea, fasting glucose, cholesterol, albu$\mathrm{min} /$ globulin ratio, cephalin flocculations, thymol turbidity, thymol flocculation, bilirubin and alkaline phosphatase.

\section{RESULTS}

The clinical response within 48 hours to the five drug variations is shown in the Table I.

In each of 22 tests in which thalidomide was given, either alone or in combination with other drugs, there was rapid clinical improvement, both subjective and objective. There was a fall in temperature and cessation of rigors. The patients slept better, nausea disappeared, and the appetite increased. Muscle, joint, nerve and testicular pains were all relieved, as were headaches. There was resorption of the skin lesions of the lepra reaction and reduction of the size of enlarged limph nodes.

All the patients receiving thalidomide gained weight, in one case from 65 to $73 \mathrm{~kg}$. within five months, and there was some decrease in the erythrocyte sedimentation rate. Changes in histological and bacteriological status, and in the response to lepromin-testing, will be detailed in a later report.

Two of the patients who had had particularly severe reactions (on the average every six weeks for 12 and 22 years) were free from reactions for six months respectively after receiving short courses of thalidomide, while continuing dapsone treatment without interruption. The first of these patients had received two courses of thalidomide in December I964 (300 mg. daily for 14 days, and $200 \mathrm{mg}$. daily for three days), and one course in March I965 (400 mg. daily for six days). The other patient had been given a single course of $400 \mathrm{mg}$. thalidomide daily for five days in January 1965 .
In one patient with severe pains and thickening of the ulnar nerve, there was relief of pain within 24 hours, and by the ninth day of treatment the nerve felt normal but still rather tender. A second patient who had severe polyneuritis also experienced relief of nerve pains within 24 hours, and the affected nerves felt normal after i 5 days of treatment, although here again there was tenderness on pressure.

Nine of the patients had active lepromatous lesions which also appear to have improved during the treatment.

In twelve tests the placebo tablet was used: in no case was there any improvement in the patient's condition.

\section{DIS C US S I O N}

Thalidomide was given to 13 unselected patients whose reactions had generally been difficult to control with stibophen or steroids. Thalidomide therapy, in contrast to a placebo, was able to cause a remissions of the signs and symptoms of lepra reaction within 48 hours in all the cases. This improvement occurred whether thalidomide was given alone or together with steroids and/or dapsone. No patient suffered from iritis or iridocyclitis during this period and therefore no evaluation could be made of the effect of thalidomide in these conditions.

\section{Side-effects}

In no case was it necessary to stop treatment because of toxic reactions. In three patients there were apparently no side-effects. The other ten patients complained of drowsiness, which was severe in two cases. Constipation, of ten severe, occurred in nine patients, usually after about three days' treatment. In seven patients this cleared up within two months of treatment, but in two patients the symptom had not yet remitted after nine and six months respectively. During the first month, dryness of the oral and nasal mucous membranes was complained of by seven patients, in two of whom it was still present six months later. Erythema of the face and chest appeared in five patients after about nine days of treatment. Pitting oedema was seen during the first month of treatment. It affected both feet in one patient, and in three patients there was recurrent oedema localised to one foot, one wrist, or one side of the face respectively. Three patients complained of mild 
transient difficulty in erection which began after about 2 months of treatment. A fourth patient, a 53 year old childless married man, has been entirely unable to experience erection since the beginning of treatment 7 months ago. In three patients a vesiculobullous eruption occurred within the first week of treatment. This disappeared within one month in two patients and within three months in the third. One patient developed a ravenous appetite, which had not remitted after six months. In a further patient an eczematous rash appeared on the abdomen on the third day and disappeared within one week.

No significant abnormalities were detected in the urine or blood examinations.

The minimum effective daily dose seemed to be $400 \mathrm{mg}$. in four divided doses. There was no apparent advantage in giving the same total dose in six divided doses. The drug appeared to be less effective when a similar dose $(6 \mathrm{mg}$. per $\mathrm{kg}$. body weight) was given intramuscularly.

Although experience is as yet limited both as regards the number of patients and the period of follow-up examinations, the immediate beneficial effect already shown in patients suffering from lepra reactions was substantiated, and it would seem to indicate that thalidomide may be helpful in the treatment of this type of patients. A study on a larger number of patients, to determine the optimum maintenance dose and the duration of treatment, is now being planned.

\section{S U M M A R Y}

I. Lepra reactions in thirteen cases of lepromatous leprosy responded within $4^{8}$ hours to treatment with thalidomide. Improvement occurred whether thalidomide was given alone or together with steroids and/or dapsone.

2. A placebo tablet given under similar conditions was ineffective.

3. The dosage used was generally $400 \mathrm{mg}$. daily given over periods of up to seven months.
4. Toxic effects were numerous, and consisted of drowsiness, constipation, dryness of the oral and nasal mucosae, erythema of face and chest, oedema localised to one extremity, mild difficulties in erection, excessive appetite, vesiculobullous and eczematous rashes. In most cases these eff ects were transient and in no case was it necessary to withdraw the drug because of the side effects.

5. During the Io-month observation period, no pathological changes were noted on fortnightly examination of urine, peripheral red and white blood cells and liver function tests.

TAB LE I

\section{Immediate Effect of 34 Assorted Therapeutic Tests in 22 Lepra Reactions}

$\begin{array}{lll}\text { Treatment } & \begin{array}{l}\text { Number of } \\ \text { Therapeutic } \\ \text { Tests }\end{array} & \begin{array}{l}\text { Impri } \\ \text { with } \\ 4^{8}\end{array} \\ & & \\ & 6 & \text { o } \\ \text { Placebo and Dapsone } & 6 & \text { o } \\ \text { Placebo alone } & 6 & \end{array}$

Thalidomide and Dapsone and prednisone I I Thalidomide and Dapsone $\quad 8 \quad 8$

$\begin{array}{lll}\text { Thalidomide alone } & \text { I3 } & \text { I3 }\end{array}$

\section{A CKNOWLEDGEMENT}

Thalidomide was put at our disposal by Taro Pharmaceutical Industries Ltd., Haifa, Israel; and Grunenthal Chemical Industries, Stolberg, W. Germany, for which grateful thanks.

\section{REFERENCES}

I. Sheskin, J. Clinical Pharmacology and Therapeutics. 'Thalidomide in the Treatment of Lepra Reactions'. Vol. 6, No. 3. p. 303, May-June ig65.

2. Sheskin, J. Dermatologia Venezolana. 'Influencia de la Talidomida en la Reaccion Leprosa'. i 965 . (In print). 